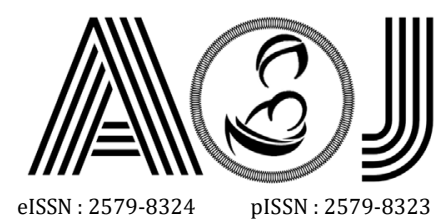

\title{
RESEARCH
}

\section{Diagnostic Test On Modified Score Of Cesarean Section History In Placenta Accreta Index In Predicting Placenta Accreta Diagnosis In Rsup Dr M Djamil}

\author{
Widayat $^{1}$, Andi Friadi ${ }^{2}$, Hafni Bachtiar ${ }^{3}$
}

Affiliation author: 1. Sungai Dareh District Hospital, Dharmasraya, West Sumatera, Indonesia; 2. Sub Division of Gynecological Oncology, Obstetrics and Gynecology Department, Faculty of Medicine, Andalas University, Dr. M. Djamil Central General Hospital Padang, West Sumatera, Indonesia; 3. Public Health Department, Faculty of Medicine, Andalas University Padang, West Sumatera, Indonesia

Correspondence to: Widayat, email: dokterwidayat@gmail.com, Hp:082392042749

\begin{abstract}
Introduction : Placenta accreta is defined as abnormal implantation of placenta villi which invades myometrium without the presence of decidua bacalis resulting in placenta that is difficult to remove. Based on the depth of invasion, placenta accreta is divided into three grades, placenta accreta, placenta increta, and placenta percreta. Placenta accreta developes if chorionic villi attaches to endometrium beyond desidua basalis. Placenta increta develops when chorionic villi invades the whole myometrium. Placenta percreta developes when chorionic villi attaches beyond myometrium reaching serous and abdominal organ. Based on clinical manifestation, placenta accreta is the common term being used. Incident of abnormal placenta invasion varies from $1: 93.000$ up to $1: 540$ pregnancy. PA incidence had increased four times from 1994 to 2002 in line with increased of caesarean section procedure. Other study showed history of caesarean section increased risk of placenta accreta up to 8,7 times. Placenta accreta index (PAI) was developed based on scoring process or various parameters assessment to help diagnose placenta accreta. The parameters including: history of caesarean section $\geq 2$ times, lacunae grade, sagittal smallest myometrial thickness, anterior placenta previa and birding vessel. High PAI indicates high risk of abnormal placenta invasion based on histology.
\end{abstract}

Objective : This study aims to investigate modified history of cesarean section score in placenta accreta index in predicting placenta accreta diagnosis in RSUP DR M Djamil Padang.

Material and methods : This was analytical study with cross sectional design. Study population was 84 placenta accreta patients in RSUP Dr. M. Djamil Padang from 2016 to 2019. Study sample was recruited using simple random sampling technique after meeting inclusion and exclusion criteria. Statistic analysis was done using Cohen's Kappa test. Diagnostic test including sensiticivy, specivicity, positive predictive value (PPV), negative predictive value (NPV), and diagnostic accuracy.

Result : Strenght of agreement diagnosis placenta accreta based on PAI showed Kappa score of 0,002 (Kappa score < 0,2) which indicated poor strength of agreement. Strenght of agreement diagnosis placenta accreta based on modified PAI showed Kappa score of 0,353 (Kappa score range from 0,21 to 0,40) which indicated fair strength of agreement. PAI diagnostic test yield sensitivity of $97,1 \%$, specificity of $2,8 \%$, positive predictive value of $48,5 \%$, negative predictive value of $50 \%$, and

Received : June $2^{\text {nd }}, 2021$ 


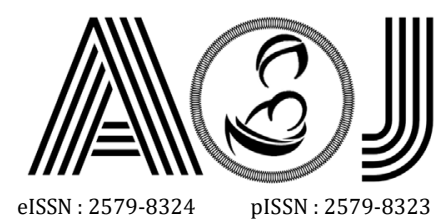
ANDALAS OBSTETRICS AND GYNECOLOGY JOURNAL

Address for Correspondence:

Editorial Room Andalas Obstetrics and Gynecology Journal, $3^{\text {rd }}$ floor of KSM of Obstetrics and Gynecology, RSUP DR. M. Djamil Padang, Jl. Perintis Kemerdekaan Padang, Sumatera Barat 25127

Website:

http://jurnalobgin.fk.unand.ac.id/index.php/JOE

accuracy of 48,6\%. Modified PAI diagnostic test yield sensitivity of 97,1\%, specificity of 38,9\%, positive predictive value of $60 \%$, negative predictive value of $93,3 \%$, and accuracy of $67,1 \%$.

Conclusion : PAI has high sensitivity, low specificity, moderate positive predictive value, moderate negative predictive value, and moderate accuration. Modified PAI has high sensitivity, moderate specificity, moderate positive predictive value, high negative predictive value, and high accuracy. PAI diagnosis has poor strength of agreement compared with pathology anatomy. Modified PAI diagnosis has fair strength of agreement compared with pathology anatomy. Modified PAI has identical sensitivity with standard PAI, meanwhile for specificity, positive predictive value, negative predictive value, and accuracy, modified PAI yields higher result compared to PAI.

Keywords: Modified score of history caesarean section, placenta accreta index, Modified placenta accreta index, diagnostic test of placenta accreta diagnosis

\section{INTRODUCTION}

Placenta accreta is defined as abnormal implantation of placenta villi which invades myometrium without the presence of decidua bacalis resulting in placenta that is difficult to remove. ${ }^{1,2}$ Based on the depth of invasion, placenta accreta is divided into three grades, placenta accreta, placenta increta, and placenta percreta. Placenta accreta developes if chorionic villi attaches to endometrium beyond desidua basalis. Placenta increta develops when chorionic villi invades the whole myometrium. Placenta percreta developes when chorionic villi attaches beyond myometrium reaching serous and abdominal organ. ${ }^{3,4}$ Based on clinical manifestation, placenta accreta is the common term being used. ${ }^{2}$

Incidence of abnormal placenta invation for placenta accreta, increta, and percreta are $81,6 \%$; $11,8 \%$; and 6,6\%; respectively. ${ }^{4}$ Placenta accreta (PA) is abnormal placentation where chorionic villi directly attaches to structure beyond myometrium. ${ }^{3}$ So thus, a portion of placenta cannot be separated after delivery which leads to severe bleeding where ermergency caesarean hysterectomy is necessary. ${ }^{5,6}$

Incident of abnormal placenta invasion varies from 1 : 93.000 up to 1 : 540 pregnancy. ${ }^{1}$ PA incidence had increased four times from 1994 to 2002 in line with increased of caesarean section procedure. ${ }^{5}$ Placenta previa and history of caesarean section are contributing factor in placenta accreta occurance. In the last 50 years, prevalence of placenta accreta has increased ten times in United States, mainly due to primary caesarean section and history of caesarean section. . $^{2,3}$ Other study showed history of caesarean section increased risk of placenta accreta up to 8,7 times. $^{7}$

Placenta accreta index (PAI) was developed based on scoring process or various parameters assessment to help diagnose placenta accreta. The parameters including: history of caesarean section $\geq 2$ times, lacunae grade, sagittal smallest myometrial thickness, anterior placenta previa and birding vessel. High PAI indicates high risk of abnormal placenta invasion based on histology. ${ }^{8,9}$ 


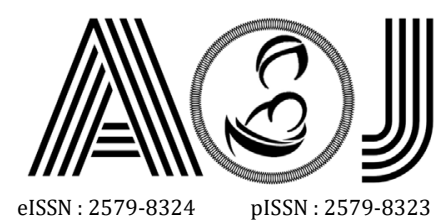

eISSN : 2579-8324
pISSN : 2579-8323

Previous study investigating PAI with placenta accreta incidence in RSUP. Dr. M. Djamil Padang in 2018 showed patients with placenta accreta had higher PAl compared with patients without placenta accreta. This study also suggested there was significant correlation between PAI score with placenta accreta case. This study was in accordance with study by Rac et al in 2014 and Nelson et al in $2016 .{ }^{10}$

Initial diagnosis of placenta accreta is made during patient first visit by converting placenta accreta index score (PAI). Patient is declared having placenta accreta if PAI score > 4. ${ }^{11,12} \mathrm{PAl}$ includes various parameter, one of them is caesarean section history, with the constant score as follows: score 0 for history of caesarean section $<2$ and score 3 for history of caesarean section $\geq 2$ times. The range of scoring range is very large ( 3 point difference), in this study, subjective SC history scores were modified for a better diagnosis of placenta accreta.If the score range is reduced or modieif modified, where the score is reduced to 2 , the PAI score might yield different diagnosis. Diagnosis is said to be accurate if the result is in accordance with the placenta accreta outcome. Placenta accreta outcome is obtained from pathology anatomy lab result and surgery report.

During initial survey on 10 medical records of 120 placenta accreta case in RSUP M Djamil, 2 patients were initially diagnose with placenta accreta but the end result was not placenta accreta. Therefore, the predictive rate of PAI is not $96 \%$ according to placenta accreta outcome after surgery, and it is assumed that the score of history of caesarean section $\geq 2 x=3$, contributed too much for PAl score which leads to false positive. In this study, author would like to investigate wether score for PAI index in the case of caesarean section $\geq 2 x=3$, might be to high to predict placenta accreta diagnosis when compared with score of 2 . Based on the comparison, we would find out which constant value yields more accurate diagnosis.

\section{METHODS}

This was an analytical study with cross sectional design. ${ }^{13,14}$ Study population was all placenta accreta patient in RSUP. Dr. M. Djamil Padang from 2016 to 2019. As many as 84 patients were recruited.

Sample was recruited using simple random sampling where the patient who met the inclusion and exclusion criteria was recruited in this study. Inclusion criterias are as follows history of cesarean section $\geq 2$ times and Medical record consisted of initial diagnosis, PAI score, surgery report, and pathology result. Exclusion criterias were inaccessible medical record, placenta accreta case with no pathology anatomy expertise. Sample was recruited using simple random sampling technique, where population who met the inclusion and exclusion criterias had equal opportunity to be recruited. ${ }^{13,14}$ From the results of the 


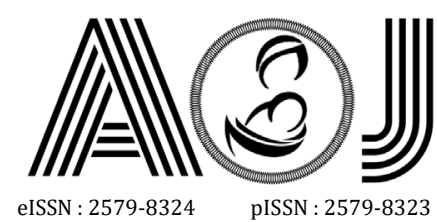

eISSN : 2579-8324
pISSN : 2579-8323

calculation using the Slovin sample formula, it was determined that the sample size was 69.4 samples (the samples were rounded up to 70 samples).

Univariate analysis was applied to every variable. Data was presented in distribution and frequency table, such as age distribution and frequency, parity, total of caesarean section history. Cohen's Kappa test was used to investigate power of consistency from diagnoses through PAI score with pathology anatomy lab result. The higher the Kappa score, the higher the strength of agreement between diagnosis based on PAI with pathology anatomy lab result. Kappa score interpretation (strength of agreement) is categorized as poor (score $<0,20$ ), fair (score $0,20-0,40)$, moderate $(0,41-0,60)$, good (score $0,61-0,80)$, and almost perfect (score $0,81-1,0) \cdot{ }^{13,14}$

Ethical clearance was granted by Research Ethics Commission Team of the RSUP M Djamil Padang prior the study. Ethical clearance was issued with statement number of 278 / KEPK / 2020.

\section{RESULTS}

\section{Sample characteristic}

Sample characteristic includes maternal age, parity, number of past caesarean section.

\subsection{Age}

Sample characteristic includes maternal age, parity, number of past caesarean section.

Table 1. Sample frequency distribution based on age

\begin{tabular}{ccc}
\hline Age (years) & F & \% \\
\hline 26 & 1 & 1,4 \\
27 & 1 & 1,4 \\
28 & 2 & 2,9 \\
29 & 4 & 5,7 \\
30 & 4 & 5,7 \\
31 & 1 & 1,4 \\
32 & 7 & 10 \\
33 & 3 & 4,3 \\
34 & 9 & 12,9 \\
35 & 10 & 14,3 \\
36 & 8 & 11,4 \\
37 & 8 & 11,4 \\
38 & 6 & 8,6 \\
39 & 1 & 1,4 \\
40 & 3 & 4,3 \\
41 & 1 & 1,4 \\
44 & 1 & 1,4 \\
\hline Total & 70 & 100 \\
\hline
\end{tabular}




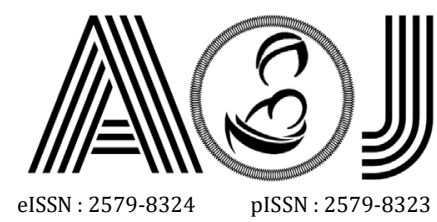
ANDALAS OBSTETRICS AND GYNECOLOGY JOURNAL

Address for Correspondence:

Editorial Room Andalas Obstetrics and Gynecology Journal, $3^{\text {rd }}$ floor of KSM of Obstetrics and Gynecology, RSUP DR. M. Djamil Padang, Jl. Perintis Kemerdekaan Padang, Sumatera Barat 25127

http://jurnalobgin.fk.unand.ac.id/index.php/JOE

The table above shows the youngest age is 26 years old and the oldest is 44 years old. The most frequent age group is 35 years old $(14,3 \%)$.

\section{Parity}

Data regarding sample's parity is shown in Table 2

Table 2. Sample frequency distribution based on parity

\begin{tabular}{ccc}
\hline Parity & f & \% \\
\hline 2 & 40 & 57,1 \\
3 & 22 & 31,4 \\
4 & 5 & 7,1 \\
5 & 2 & 2,9 \\
6 & 1 & 1,4 \\
\hline Total & 70 & 100 \\
\hline
\end{tabular}

The table above shows sample parity range $2-6$. Minimum parity is 2 , and maximum parity is 6 . The most frequent parity is $2(40 \%)$.

\subsection{History of caesarean section}

Data regarding of caesarean section history is shown in Table 3

Table 3. Sample frequency distribution based on history of caesarean section

\begin{tabular}{ccc}
\hline History of CS & $\mathbf{f}$ & $\%$ \\
\hline 2 & 55 & 78,6 \\
3 & 14 & 20 \\
4 & 1 & 1,4 \\
\hline Total & 70 & 100 \\
\hline
\end{tabular}

The table above shows range of caesarean section history is $2 x-4 x$, the lowest number of caesarean section history is $2 x$, and the highest is $4 x$. The most frequent number of caesarean section history is $2 x(55 \%)$.

\subsection{PAI Score}

PAl score was obtained by calculating PAl score using the constant history of caesarean section $\geq 2 x=3$, as shown in table 4

Tabel 4. Sample frequency distribution based on PAI score

\begin{tabular}{ccc}
\hline PAI score & F & \% \\
\hline 4 & 2 & 2,9 \\
4,25 & 3 & 4,3 \\
4,5 & 2 & 2,9
\end{tabular}




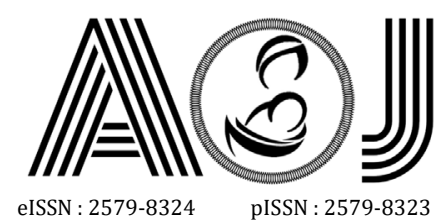

eISSN : 2579-8324 ANDALAS OBSTETRICS AND GYNECOLOGY JOURNAL

Address for Correspondence:

Editorial Room Andalas Obstetrics and Gynecology Journal, $3^{\text {rd }}$ floor of KSM of Obstetrics and Gynecology, RSUP DR. M. Djamil Padang, Jl. Perintis Kemerdekaan Padang, Sumatera Barat 25127

Website:

http://jurnalobgin.fk.unand.ac.id/index.php/JOE

\begin{tabular}{ccc}
5 & 8 & 11,4 \\
5,25 & 1 & 1,4 \\
5,5 & 6 & 8,6 \\
5,75 & 4 & 5,7 \\
6 & 5 & 7,1 \\
6,5 & 5 & 7,1 \\
7,5 & 2 & 2,9 \\
7,75 & 1 & 1,4 \\
8 & 4 & 5,7 \\
8,25 & 2 & 2,9 \\
8,5 & 14 & 20 \\
9 & 11 & 15,7 \\
\hline Total & 70 & 100
\end{tabular}

The table above shows range of PAl score among participant starts from $4-9$ with the lowest and highest score are 4 and 9, respectively. The most frequent score is 8,5 (20\%).

\subsection{Modified PAI Score}

Modified PAI score was obtained by calculating total PAI score using constant history of caesarean section score $\geq 2 x=2$, as shown in Table 5

Table 5. Sample frequency distribution based on modified PAl score

\begin{tabular}{ccc}
\hline Modified PAI score & F & $\%$ \\
\hline 3 & 2 & 2,9 \\
3,25 & 3 & 4,3 \\
3,5 & 2 & 2,9 \\
4 & 8 & 11,4 \\
4,25 & 1 & 1,4 \\
4,5 & 6 & 8,6 \\
4,75 & 4 & 5,7 \\
5 & 5 & 7,1 \\
5,5 & 5 & 7,1 \\
6,5 & 2 & 2,9 \\
6,75 & 1 & 1,4 \\
7 & 4 & 5,7 \\
7,25 & 2 & 2,9 \\
7,5 & 14 & 20 \\
8 & 11 & 15,7 \\
\hline Total & 70 & 100 \\
\hline
\end{tabular}

The table above shows range of modified PAI score starts from $3-8$, where the lowest and highest score are 3 and 8 , respectively. The most frequent score is 7,5 (20\%).

Received : June $2^{\text {nd }}, 2021$

Accepted: June $25^{\text {th }}, 2021$

Correspondence: Widayat, email: dokterwidayat@gmail.com 


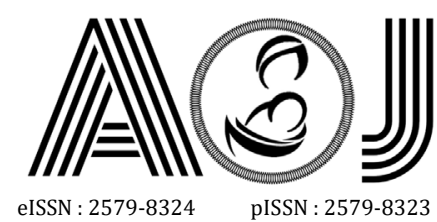

eISSN : 2579-8324
pISSN : 2579-8323

Editorial Room Andalas Obstetrics and Gynecology Journal, $3^{\text {rd }}$ floor of KSM of Obstetrics and Gynecology, RSUP DR. M. Djamil Padang, Jl. Perintis Kemerdekaan Padang, Sumatera Barat 25127

Website:

http://jurnalobgin.fk.unand.ac.id/index.php/JOE

\section{Diagnostic strength of placenta accreta based on PAI}

Strenght of agreement of placenta accreta diagnosis based on PAI was investigated using Cohen's Kappa test. The result is shown in Table 6.

Table 6. Cohen's Kappa test result on accuracy of placenta accreta diagnosis based on PAI

\begin{tabular}{|c|c|c|c|c|c|}
\hline & & \multicolumn{3}{|c|}{ PAI } & \multirow[b]{2}{*}{ Kappa } \\
\hline & & $\begin{array}{l}\text { Plaenta } \\
\text { accreta }\end{array}$ & $\begin{array}{c}\text { Not } \\
\text { placenta } \\
\text { accreta }\end{array}$ & Total & \\
\hline & Placenta accreta & 33 & 1 & 34 & \\
\hline \multirow[t]{2}{*}{$\begin{array}{l}\text { Pathology } \\
\text { anatomy } \\
\text { (PA) }\end{array}$} & $\begin{array}{c}\text { Not placenta } \\
\text { accreta }\end{array}$ & 35 & 1 & 36 & -0.002 \\
\hline & Total & 68 & 2 & 70 & \\
\hline
\end{tabular}

Table 6 shows Cohen's Kappa test for PAI where Kappa score $=-0,002$ (Kappa score $<$ 0,2 ). This result indicated Cohen's Kappa has poor strength of agreement. This concludes PAI diagnosis has poor strength of agreement with the result from pathology anatomy.

\section{Diagnostic strength of placenta accreta based on modified PAI}

Strength of agreement placenta accreta diagnosis based on modified PAI was investigated using Cohen's Kappa test. The result is shown in table 7.

Table 7. Cohen's Kappa test result on accuracy of diagnosis placenta accreta based on modified PAI

\begin{tabular}{|c|c|c|c|c|c|}
\hline & & \multicolumn{3}{|c|}{ Modified PAI } & \multirow[b]{2}{*}{ Карра } \\
\hline & & $\begin{array}{c}\text { Placenta } \\
\text { accreta }\end{array}$ & $\begin{array}{c}\text { No } \\
\text { placenta } \\
\text { accreta }\end{array}$ & Total & \\
\hline \multirow{3}{*}{$\begin{array}{c}\text { Pathology } \\
\text { anatomy } \\
\text { (PA) }\end{array}$} & $\begin{array}{l}\text { Placenta } \\
\text { accreta }\end{array}$ & 32 & 2 & 34 & \multirow{3}{*}{0.353} \\
\hline & $\begin{array}{c}\text { No placenta } \\
\text { accreta }\end{array}$ & 22 & 14 & 36 & \\
\hline & Total & 54 & 16 & 70 & \\
\hline
\end{tabular}

Table 3 shows Cohen's Kappa test for modified PAI, where Kapp score = 0,353 (Kappa score was in the range of 0,21-0,40). This indicates Cohen's Kappa test has fair strength of agreement. This result concludes modified PAI diagnosis has fair strength of agreement with pathology anatomy result. 


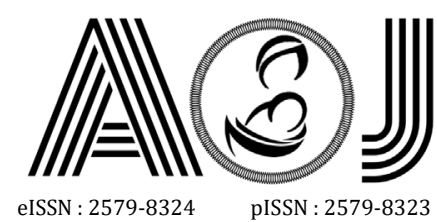

eISSN : 2579-8324

Editorial Room Andalas Obstetrics and Gynecology Journal, $3^{\text {rd }}$ floor of KSM of Obstetrics and Gynecology, RSUP DR. M. Djamil Padang, Jl. Perintis Kemerdekaan Padang, Sumatera Barat 25127

Website:

http://jurnalobgin.fk.unand.ac.id/index.php/JOE

\section{Diagnostic test}

Diagnostic test includes sensitivity, specificity, positive predictive value (PPV), negative predictive value (NPV), accuration of PAI and modified PAI diagnosis.

\subsection{PAl diagnostic test}

The following $2 \times 2$ table presents diagnostic test.

Table 8. Table $2 \times 2$ for diagnosis placenta accreta based on PAI

\begin{tabular}{ccccc}
\hline & & \multicolumn{3}{c}{ Pathology Anatomy (PA) } \\
\cline { 3 - 5 } & Placenta accreta & 33 & No placenta & Total \\
accreta & Placeta & (a) & (b) & 68 \\
& No placenta accreta & 1 & 1 & 2 \\
& PAI & (c) & (d) & 70 \\
& Total & 34 & 36 & 70 \\
\hline
\end{tabular}

The following values are calculated based on table 4.1 :

a. Sensitivity

$$
\frac{a}{a+c} \times 100 \%=\frac{33}{33+1} \times 100 \%=97,1 \%
$$

b. Specificity

$$
\frac{d}{b+d} \times 100 \%=\frac{1}{35+1} \times 100 \%=2,8 \%
$$

c. Positive predictive value (PPV)

$$
\frac{a}{a+b} \times 100 \%=\frac{33}{33+35} \times 100 \%=48,5 \%
$$

d. Negative predictive value (NPV)

$$
\frac{d}{c+d} \times 100 \%=\frac{1}{1+1} \times 100 \%=50 \%
$$

e. Accuracy

$$
\frac{a+d}{(a+b+c+d)} \times 100 \%=\frac{33+1}{(33+22+1+14)} \times 100 \%=48,6 \%
$$




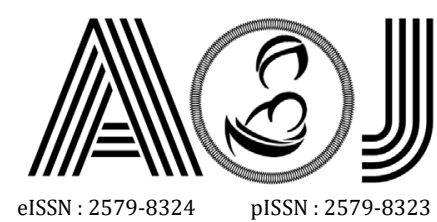

eISSN : 2579-8324

Based on the previous calculation, PAl yields sensitivity of $97,1 \%$ and specificity of 2,8\%, positive predictive value (PPV) 48,5\%, negative predictive value (NPV) $50 \%$, and accuracy of $48,6 \%$.

\subsection{Modified PAI diagnostic test}

The following $2 \times 2$ table present modified PAl diagnostic test

Table 9. 2x2 Table for diagnosis placenta accreta based on modified PAI

\begin{tabular}{ccccc}
\hline & & \multicolumn{3}{c}{ Pathology anatomy (PA) } \\
\cline { 3 - 5 } & Placenta accreta & 33 & No placenta & Total \\
\hline \multirow{3}{*}{ Modified PAl } & (a) & (b) & 55 \\
& No placenta accreta & 1 & 14 & 15 \\
& Total & (c) & (d) & 70 \\
\hline
\end{tabular}

The following values are calculated based on table 4.2 :

a. Sensitivity

$$
\frac{a}{a+c} \times 100 \%=\frac{33}{33+1} \times 100 \%=97,1 \%
$$

b. Specivicity

$$
\frac{d}{b+d} \times 100 \%=\frac{14}{22+14} \times 100 \%=38,9 \%
$$

c. Positive predictive value (PPV)

$$
\frac{a}{a+b} \times 100 \%=\frac{33}{33+22} \times 100 \%=60 \%
$$

d. Negative predictive value (NPV)

$$
\frac{d}{c+d} \times 100 \%=\frac{14}{1+14} \times 100 \%=93,3 \%
$$

e. Accuracy

$$
\frac{a+d}{(a+b+c+d)} \times 100 \%=\frac{33+14}{(33+22+1+14)} \times 100 \%=67,1 \%
$$

Based on the calculation, modified PAI yields sensitivity of $97,1 \%$, specificity $38,9 \%$, positive predictive value (PPV) $60 \%$, negative predictive value (NPV) $93,3 \%$, and accuracy of $67,1 \%$. 


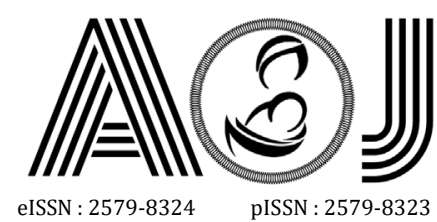

eISSN : 2579-8324
pISSN : 2579-8323

Editorial Room Andalas Obstetrics and Gynecology Journal, $3^{\text {rd }}$ floor of KSM of Obstetrics and Gynecology, RSUP DR. M. Djamil Padang, Jl. Perintis Kemerdekaan Padang, Sumatera Barat 25127

Website:

http://jurnalobgin.fk.unand.ac.id/index.php/JOE

\section{Comparison of PAI and modified PAI diagnostic test}

Comparison of PAI and modified PAI diagnostic test is presented on the following table.

Table 10. Comparison of PAI and modified PAI diagnostic

\begin{tabular}{ccc}
\hline Diagnostic test & PAI (\%) & Modified PAI (\%) \\
\hline Sensitivity & 97,1 & 97,1 \\
SPecificity & 2,8 & 38,9 \\
PPV & 48,5 & 60 \\
NPV & 50 & 93,3 \\
Accuracy & 48,6 & 67,1 \\
\hline
\end{tabular}

Based on the table above, modified PAI has identical sensitivity value with standard PAI, meanwhile specificity, positive predictive value, negative predictive value, and accuracy of modified PAI are higher compared with PAI.

\section{DISCUSSION}

\section{Subjects Characteristics}

The results showed that subjects' age ranged from 26-44 years and the oldest age in this study was 35 years old. This was in line with the study conducted by Tovbin et al at the University of Tel Aviv (2016) that the mean age of patients on the sonographic evaluation of placenta accreta was $33.8 \pm 4.5$ years. ${ }^{15}$

In this study, subjects' parity ranged between 2 to 6 parities. The lowest subject's parity was 2 , and the highest was 6 and 2 was the most found parity (40\%). This, as reported Belfort et al. study in 2010, was associated with multiparity, but the frequency of placenta accreta (PA) incicident is undetermined. , $^{46,17}$

This study showed subjects' c-section history was between 2 to 4 times. The lowest csection history was 2 times and the highest was 4 times and 2 history of previous c-section was the most found in this study (55\%). This result was in line with the study conducted by Baughman et al. in 2008 that Placenta previa and history of previous cesarean section were the most significant risk factors for placenta accreta (PA). Placenta previa in patients with two or more history of previous section cesarean increased the risk of placenta accreta (PA) up to $40 \%$ to $60 \% .^{3,18,19}$

Based on this research, it is also known that the highest PAI score frequency was 8.5. Rac in 2014 also stated that risk of invasion was proprtional to placenta accreta Index (PAI) score, where score of $>8$ increased the risk of placental invasion up to $96 \%$. So it can be concluded that the higher the PAI score, the higher the risk of placenta accreta. ${ }^{12}$ The most common modified PAI score was 7,5. Modified PAI reduced the PAl score by one point in the history of previous c-section $\geq 2$ times. Hence, if the standard PAI score is known to be 8.5 , then the modified PAI will automatically be 7.5. 


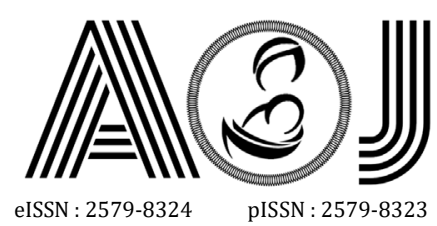

\section{Accuracy of PAI and Modified PAI in Diagnosing Placenta Accreta}

Cohen's Kappa statistycal analusus showed that PAI has low to poor Strength of Agreement with the results of Pathology examination, while PAI modification has sufficient / fair Strength of Agreement with the result of Pathology examination. Modification PAl has a better Strength of Agreement than PAI. In line with this results, the diagnostic test results also show that modified PAI has a higher sensitivity, specificity, Positive Predictive Value (PPV), Negative Predictive Value (NPV) and accuracy than PAI.

Diagnostic test is a test performed to strengthen conclusions about the comparison of the accuracy of modified PAI and PAI in predicting the diagnosis of placenta accreta. The diagnostic test used in this study consisted of sensitivity, specificity, Positive Predictive Value (PPV), Negative Predictive Value (NPV) and accuracy.

The calculation of the sensitivity value aims to determine the percentage of samples diagnosed with placenta accreta based on PAI score and diagnosed with placenta accreta according to the results of the anatomical pathology examination, or in other words it is also known as True Positive. The results of this study indicated that modified PAI and PAI have the same sensitivity.

The calculation of the specificity aims to determine the percentage of samples not diagnosed with placenta accreta based on PAl score and not diagnosed with placenta accreta according to the results of anatomical pathology examination, or in other words also known as True Negative. The results of this study indicated that modified PAI has better specificity than PAI.

Positive predictive value (PPV) is calculated to see the percentage of samples diagnosed with placenta accreta based on PAI score but not diagnosed with placenta accreta according to the results of anatomical pathology examination, which also known as False Positive. In this study, modified PAI has a better PPV than PAI.

Negative predictive value (NPV) is calculated to determine the percentage of samples not diagnosed with placenta accreta based on PAI score but diagnosed with placenta accreta according to the results of the anatomical pathology examination, which also known as False Negative. In this study, modified PAI had better NPN than PAI.

From the overall value of the diagnostic test, it can be summarized in a value called accuracy. Accuracy is the proportion of true value/test correctly (true positive + true negative) among all the samples examined. The accuracy of modified PAl in this study was better than the accuracy of PAI.

Here are some of the previous studies on the Placenta Accreta Index (PAI). Study conducted by Nelson et al (2017) in 66 cases showed that the application of the PAI method 


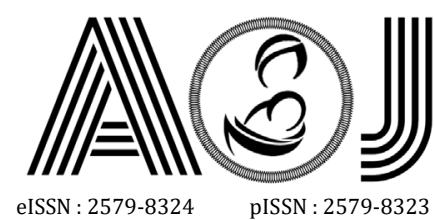

eISSN : 2579-8324
pISSN : 2579-8323

increased diagnostic accuracy by $80.3 \%$ compared to the diagnostic accuracy of ultrasound $(66.6 \%)$ and increasing the sensitivity of ultrasound diagnosis (34\% to $60 \%, p=0.005$ ). Specificity (100\%), PPV (100\%), and NPV (55\%) were also higher using the PAl score in patients with at least 1 previous history of c-section, whereas the application of PAI in all cases of placenta accreta resulted in 52\% sensitivity, $100 \%$ specificity, PPV $100 \%$ and NPV 73\%. ${ }^{11}$ Ellakwa et al. research in 2019 showed that all parameters of the placenta accreta index were statistically significant and score 4 was found to be the best cut-off point in diagnosing placenta accreta. In that study, the sensitivity of score 4 of placenta accreta index was $89,5 \%$, while the specificity was $97.6 \%{ }^{12,20}$

Another research conducted Samosir et al (2017) regarding the use of placenta accreta index (PAI) to predict abnormal placenta invasion at Hasan Sadikin Hospital in Bandung, showing that placenta accreta index (PAI) has a sensitivity of $70 \%$, specificity of $81.8 \%$, positive. predictive value (PPV) $77.8 \%$, and negative predictive value (NPV) $75 \% .{ }^{9}$ According to the research of Tovbin et al (2016), the overall sensitivity (Sn) of the high probability score was $69.6 \%(16 / 23)$. Specificity (Sp) of a high probability score was $98,7 \%$ (235/239). Positive predictive value (PPV) and begative predictive value (NPV) were $84.2 \%$ (16/19) and 97.1\% (232/237), respectively. The overall detection/sensitivity rate for high or moderate probability scores was $91.3 \%(21 / 23)$ and the specificity was $94.6 \%(220 / 235) .{ }^{15}$ Study conducted by Li Luo et al ( 2019 ) using a threshold score showed that this scoring system produces high positive predictive values (PPV $95.44 \%$ and $81.81 \%$ ) for without PAS (Placenta Accreta Spectrum) and percreta, and moderate ( $80.26 \%$ and $75.47 \%$ ) for accreta and increta. In addition, the system received a high negative predictive value (NPV=5.44\%) and a low false positive rate $=3.32 \%$. Without Placenta Accreta Spectrum (PAS) had shown a very low false positive rate at $4,56 \%$. The threshold scores for the predictive accreta, increta, and percreta were $2.25-6.2,6.2-8.95$, and $\geqq 8.95$, respectively, with positive and negative predictive values, and false-positive rates of the scoring systems were $96.68 \%, 95.44 \%$, and $3.32 \%$ respectively. ${ }^{15,16}$

The Placenta Accreta Index (PAI) is an index determined from the assessment of various parameters to simplify diagnosing placenta accreta. The diagnosis of placenta accreta is established at the time of admission by converting the score of placenta accreta Index (PAI). Patients was diagnosed with placenta accreta if the score $>4 .{ }^{11}$ Placenta accreta Index (PAI) covers a wide range of parameters, one of them is previous history of c-section. previous history of c-section had the following scores :8,11

a) History of c-section $<2$ times is assigned a score of 0

b) History of c-section $\geq 2$ times is assigned a score of 3 


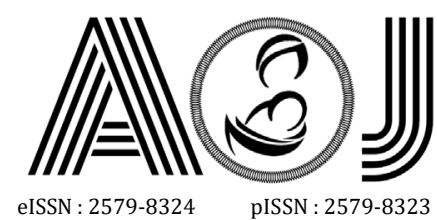

eISSN : 2579-8324
pISSN : 2579-8323

The gap scores in points $a$ ) and b) above is very large ( 3 points apart). In this study, the researchers tried to compare the diagnostic accuracy of PAI (PAI with a history score of csection $\geq 2$ times $=3$ ) and through calculating modified PAI (PAI with a history score of csection $\geq 2$ times $=2$ ). ${ }^{15}$ The results of this study proved that modified PAI had better accuracy.

Based on the diagnostic test theory approach as previously described, the authors will explain why modified PAI has better accuracy than PAI.

a) PAI modification tend to have a statistically better test results than PAI due to the following reasons:

1) The Cohen's Kappa statistical test is a test to compare any differences between two types of measuring instruments. The measuring instruments intended in this study was PAI and the results of the anatomical pathology examination. Because in this study there were two types of PAI scores (modified PAI and PAI), the Cohen's Kappa statistical test was carried out twice, including:

- Cohen's Kappa test PAI * Anatomical Pathology

- Cohen's Kappa test modified PAI * Anatomical Pathology

2) The Cohen's Kappa test is expressed in Kappa value $(<0.02-1.00)$, where the PAI value of Kappa $<0.02$ means that the value of strength of agreement is low (poor) and modified PAI of the Kappa value $=0.353$ means the value of the strength of agreement is sufficient (fair). Hence, the conclusion obtained was that modified PAI was better than PAI in predicting the placenta accreta .

3) True diagnosis can be true positive and true negative (can be seen in $2 \times 2$ table). This means that the diagnosis obtained by calculating the PAI score which is the same as the outcome of Anatomic Pathology examination, known as true diagnosis.

4) Modified PAI is PAI with the score is lowered by one point, on the former parameter c-section $\geq 2$ times. A decrease in this score can lead to a change in the diagnosis from placenta accreta to non-placenta accreta, as illustrated by the arrow shown in the illustration below ( $2 \times 2$ Table) :

\begin{tabular}{cccc}
\hline & & \multicolumn{2}{c}{ Anatomical Pathology (PA) } \\
\cline { 3 - 4 } & & Placenta Acreta & No Placenta Acreta \\
\hline \multirow{3}{*}{ PAI } & Placenta & (a) & (b) \\
& Acreta & True Positive & False Positive \\
& Not Placenta & (c) & (d) \\
& Acreta & False Negative & True Negative \\
\hline
\end{tabular}

5) As can be seen in the table above, changing the diagnosis will also shift the position of sample from quadrant (a) to quadrant (c) and from quadrant (b) to quadrant (d) 


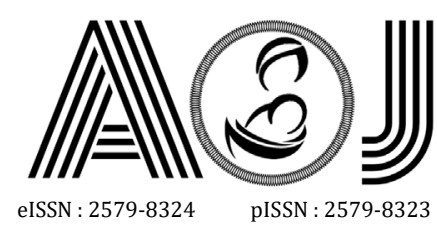

eISSN : 2579-8324
pISSN : 2579-8323

6) The shifting of samples to quadrant (c) is probably in small number because the average sample diagnosed with placenta accreta has a PAI score $>5$, so that if it is lowered by one point, it will change to $>4$ (which still converted as placenta accreta).

7) The shifting of sample from quadran (b) to quadran (d) causes an increase in the significance of the Cohen's Kappa test results on modified PAI.

b) Modified PAI tend to have a better diagnostic test results compared to PAI due to the following reasons:

1) The diagnostic test used in this study consists of sensitivity, specificity, Positive Predictive Value (NPP), Negative Predictive Value (NPN) and accuracy.

2) As explained in point a) above, that a decrease in the PAl score will have an impact on a change in diagnosis, in turn, it will also have an impact on increasing the true negative value/specificity, while true positive/sensitivity may decrease, but not too significant, or even there may not be any decrease in true positive/sensitivity. True positive/sensitivity and true negative/specificity are indicators that determine the accuracy of a diagnostic test.

3) From the overall value of the diagnostic test, it can be summarized in a value called accuracy. Accuracy is the proportion of true values (true positive + true negative) among all examined samples. By increasing the True Positive and True Negative values, the accuracy value of modified PAI will automatically increase.

\section{CONCLUSION}

1. PAl had high sensitivity, weak specificity, moderate Positive Predictive Value (PPV), moderate Negative Predictive Value (NPV) and moderate accuracy.

2. Modified PAI had high sensitivity, moderate specificity, moderate positive predictive value (PPV), high negative predictive value (NPV) and high accuracy.

3. Diagnosis with PAI had low (poor) strength of agreement with the results of anatomic pathology examination.

4. Diagnosis with modified PAI had sufficient (fair) strength of agreementwith the results of anatomic pathology examination.

5. Modified PAI has the same sensitivity as standard PAI, while the specificity, Positive Predictive Value (PPV), Negative Predictive Value (NPV) and the accuracy of modified PAI were higher than PAI. 


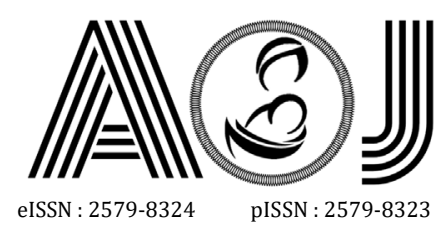
ANDALAS OBSTETRICS AND GYNECOLOGY JOURNAL

Address for Correspondence:

Editorial Room Andalas Obstetrics and Gynecology Journal, $3^{\text {rd }}$ floor of KSM of Obstetrics and Gynecology, RSUP DR. M. Djamil Padang, Jl. Perintis Kemerdekaan Padang, Sumatera Barat 25127

Website:

http://jurnalobgin.fk.unand.ac.id/index.php/JOE

\section{REFFERENCES}

1. Cunningham FG. Williams Obstetrics, $25^{\text {th }}$ Edition. Chapter 35-Obstetrics Haemorrhage. United States of America: McGraw-Hill Education; 2018. p. 776780

2. Bowman ZS. Accuracy of Ultrasound for Prediction of Placenta Accreta. USA: American Journal of Obstetrics and Gynecology; 2014. p. 177.ei - e7.

3. Baughman, WC. Placenta Accreta Spectrum Of US and MR Imaging Findings Vol 28.Ohio: RadioGraphics Journal from The Departement Of Radology and Obstetrics and Gynecology; 2008. p. 1905-1917.

4. Belfort MA. Publication American Journal of Obstetrics and Gynecology :Placenta Accreta.Washington: Committee, Society for Maternal-Fetal Medicine; 2010.p. 430- 7 .

5. Stirnemann J. Screening for Plasenta Accreta at 11-4 Weeks of Gestation.Washington:American Journal of Obstetrics and Gynecology; 2011.p. 547.ei-e5.

6. Afzal S, Masroor I.Ultrasonographic Diagnosis of Placenta Accreta. Pakistan: Pakistan Journal Radiology; 2010. p. 165-7.

7. Riteau $A$, et al. Accuracy of Ultrasonography and Magnetic Resonance Imaging $n$ Diagnosis of Plasenta Accreta.Vol 9.Issue 4.France ;2014.p.1-9.

8. Martha R, Dashe, et al.Ultrasound Predictors of Placental Invasion: The Placenta Accreta Index. USA: American Journal of Obstetrics and Gynecology; 2015.p. 343.ei - 343.e7.

9. Samosir SM, Irianti S, dan Tjahyadi D. Diagnostic test of placenta accreta index score (PAIS) as supporting prenatal diagnosis and outcomes of maternal neonatal in abnormally invasive placenta management at general hospital of Hasan Sadikin Bandung. Int J Reprod Contracept Obstet Gynecol, 2017:6(9); 3765-9.

10. Firmana, I. Ariadi. Hubungan Skor Plasenta Akreta Indeks (PAI) dengan Kejadian Plasenta Akreta pada pasien bersalin di bagian kebidanan RSUP. dr. M. Djamil Padang. Andalas Obstetrics and Gynecology Journal. 2019.

11. Nelson T, Chang E et al. Validation of the Placenta Accreta Index (PAI): Improving the antenatal diagnosis of the morbidly adherent placenta. USA: American Journal of Obstetrics and Gynecology; 2017. p.209.

12. Ellakwa, $\mathrm{H}$ et al.Evaluation of placenta accreta index to predict placental invasion in patients with placenta previa. Faculty of Medicine, Menoufia University . Menoufia Medical Journal. 2019. Vol 32 no 4.

13. Sudigdo S, Sofyan I. Dasar Dasar Metodologi Penelitian Klinis. Sagung Seto. Edisi 4. 2011. 


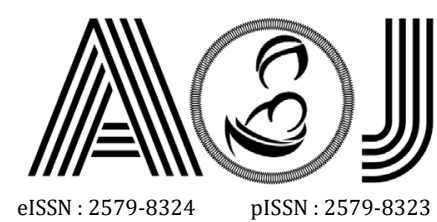

eISSN : 2579-8324 ANDALAS OBSTETRICS AND GYNECOLOGY JOURNAL

Editorial Room Andalas Obstetrics and Gynecology Journal, $3^{\text {rd }}$ floor of KSM of Obstetrics and Gynecology, RSUP DR. M. Djamil Padang, Jl. Perintis Kemerdekaan Padang, Sumatera Barat 25127

14. Hastono S. Analisis Data. Fakultas Kesehatan Masyarakat Universitas Indonesia. 2006.

15. Tovbin J, Maymon R et al. Predicting of morbidly adherent placenta using a scoring system: A prospective study. Israel: Department of Obstetrics and Gynecology. Assaf Harofeh Medical Center; 2016.

16. Li luo et al. Scoring system for the prediction of the severity of placenta accreta spectrum in women with placenta previa: a prospective observational study. Archives of Gynecology and Obstetrics. Springer. 2019.

17. Jauniaux E, Collins S, Burton GJ. Placenta accreta spectrum: pathophysiology and evidence-based anatomy for prenatal ultrasound imaging. Am J Obstet Gynecol. 2018 Jan;218(1):75-87. doi: 10.1016/j.ajog.2017.05.067. Epub 2017 Jun 24. PMID: 28599899.

18. Berkley EM, Abuhamad A. Imaging of Placenta Accreta Spectrum. Clin Obstet Gynecol. 2018 Dec;61(4):755-765. doi: 10.1097/GRF.0000000000000407. PMID: 30339609.

19. Society of Gynecologic Oncology; American College of Obstetricians and Gynecologists and the Society for Maternal-Fetal Medicine, Cahill AG, Beigi R, Heine RP, Silver RM, Wax JR. Placenta Accreta Spectrum. Am J Obstet Gynecol. 2018 Dec;219(6):B2-B16. doi: 10.1016/j.ajog.2018.09.042. PMID: 30471891.

20. Carusi DA. The Placenta Accreta Spectrum: Epidemiology and Risk Factors. Clin Obstet Gynecol. 2018 Dec;61(4):733-742. doi: 10.1097/GRF.0000000000000391. PMID: 30204619. 